\title{
Curbing Drug Use in the Seychelles through Regulation beyond Legislation
}

\author{
Amelie Nourrice
}

\begin{abstract}
This article was written with the intention of figuring out why the Seychelles has been unable to douse the drug epidemic despite apparent vigorous efforts on the part of the government and of finding a new way of curtailing drug abuse without relying entirely on legislation, which although in some ways are necessary, has on its own, been incapable serving efficacy.

The article introduces a four step pyramid giving effect to a responsive approach which Braithwaite suggests lays 'emphasis on the pyramidal regulatory structure, on regulation through engagement and dialogue rather than by dictat, on bringing third parties into what had been previously characterized as a binary regulator/regulatee interaction, and on the concept of the benign big gun.'

Thus, by building a drug user's capacity and providing the apt restorative treatment before labelling him as an offender and subjecting him to incapacitation, the drug user is offered an opportunity at restoration.

The criteria featuring in the pyramid must work in conjunction with the law as this combination and the use of various actors at each tier is a significant way to effectively execute government policies without that strict and direct regulator/ regulatee relationship whereby the former would otherwise lord it over the latter.
\end{abstract}

Keywords: Seychelles, legislative drafting, drug abuse, drug abuse legislation.

\section{A Introduction}

\section{History}

For years, the islands of Seychelles have been plagued with a heroin epidemic that has left many in despair. In 1998, the islands of Seychelles experienced a surge in heroin usage, ${ }^{1}$ which transformed the once serene and idyllic islands, formerly dubbed 'paradise on earth', into an agonizing ordeal, putting a rather sharp damper on the freedom previously enjoyed by the people.

To deal with the crisis, the National Drugs Enforcement Agency (NDEA) was established in 2008, with the clear intention of conducting and coordinating endeavours to combat drug-related offences in Seychelles. However, over the

* Amelie Nourrice is Legislative Drafter, Office of the Attorney General, The Seychelles.

1 Seychelles Nation, 'New R14m centre for addicts to replace one that burned' (March 2013)

www.nation.sc/archive/237800/new-r14m-centre-for-addicts-to-replace-one-that-burned

<accessed 5 July 2020>. 
years, the Agency itself faced allegations ranging from corruption to malpractice as drug offences surged. In February 2017, the Irish nationals occupying leading positions in NDEA and the Seychelles Financial Intelligence Unit vacated their posts, and later the islands, ${ }^{2}$ following the release by members of Parliament of the Public Accounts Committee report pertaining to irregular payments, in violation of legal procedures, made to two offshore companies based in Mauritius.

The functions of the NDEA were subsequently integrated within the police department, with the roles and functions of the former falling directly under the supervision of the Commissioner of Police and the newly established AntiNarcotics Bureau, ${ }^{3}$ giving new hope for a more sober future. When Labonte took over as Chief Officer of NDEA in March 2017, the new NDEA management commenced the Netwayaz (Cleaning) operations. Joint operations with police officers were conducted, resulting in an increase in arrests and in seizures of illegal drugs.

\section{Hypothesis and Methodology}

Despite these efforts, the inhabitants of the islands remain eminently leery of the violence and theft associated with the exponential increase in drug usage. The islands harbour a firmly established dilemma of having, according to Saigal, the worst heroin problem globally, with $10 \%$ of its working population being habituated to this detrimental substance. ${ }^{4}$

A government endeavouring to curtail drugs can either target the drug traffickers and those who facilitate the illegal activities or aim to rehabilitate the drug users, who are often regarded as victims of a disease. It is for what appears to be an inability on the part of authorities concerned to track and apprehend traffickers that the drug user is made the cynosure of this article. Dr. Patrick Herminie, the current head of the Prevention of Drug Abuse and Rehabilitation Agency in Seychelles has implemented a Portuguese-based drug policy, whereby drug addiction is deemed rather as a chronic disease to be treated, thereby steering away from what was previously a more punitive approach. ${ }^{5}$ However, it cannot be presumed that all drug users are absolute victims, as many choose to consume heroin (despite the surfeit of information pounded on the public on a daily basis), oftentimes making victims of the very people who care for them. In a survey aimed at families of avid drug users, many complained of the latter's violent and thieving tendencies having an emotionally exhausting impact on them.

Thus, although this article intends to target drug users and to show deliberate sympathy towards them, they will not be perceived solely as victims of

2 Seychelles Nation, 'Transforming year for drug enforcement in Seychelles' (December 2017) www.nation.sc/archive/257141/transforming-year-for-drug-enforcement-in-seychelles <accessed 26 June 2020〉.

3 Ibid.

4 Kanika Saigal, 'Why Seychelles has world's worst heroin problem' (November 2019) www.bbc.co.uk/news/world-africa-50488877 <accessed 10 June 2020>.

5 AFP News Agency, 'Seychelles: Addicts struggle as country battles heroin crisis|AFP' (February 2020) www.youtube.com/watch?v=xpPtlD4zpCE <accessed 21 September 2020〉. 


\section{Figure 1 Responsive Regulatory Pyramid}



a disease as drug users in Seychelles tend to exhibit antagonistic behaviours. It is on this basis that I feel it propitious to employ the following pyramid, making users responsible, at some point, for their actions when they persist in their deviant behaviours.

I hypothesize thus that the effort in the curbing of drug use in Seychelles far transcends words that feature in legislation, but can only serve efficacy the extent to which regulators achieve their goals ${ }^{6}$ - by way of a cohesive and practical effort. This article proposes a new way to curtail drug use in a manner that promptly benefits both the drug user and the community as soon the effort is launched by employing a responsive approach reflected in John Braithwaite's pyramid, ${ }^{7}$ which features the four criteria illustrated, all of which are to be applied in conjunction with the law.

Braithwaite defines the responsive approach as that approach which lays

emphasis on the pyramidal regulatory structure, on regulation through engagement and dialogue rather than by dictat, on bringing third parties into what had been previously characterized as a binary regulator/regulatee interaction, and on the concept of the benign big gun. ${ }^{8}$

The rationale behind this being that "unless there is some third party (or a number of them) in the regulatory game, regulation will be captured and corrupted by money power". ${ }^{9}$ While responsive regulations have been popularized

$6 \quad$ Helen Xanthaki, Drafting Legislation (Hart Publishing Ltd 2014): 5.

7 John Braithwaite, 'War, crime, regulation', http://johnbraithwaite.com/responsive-regulation/ <accessed 7 August 2020>.

8 Cristie Ford and Natasha Affolder, 'Responsive regulation in context, circa 2011' (2011) 44 UBC L Rev 463.

$9 \quad$ Braithwaite, note 7. 
in environment and peace building, ${ }^{10}$ this approach also seemingly bodes well for the curbing of alcoholism.

This article will therefore

a describe current efforts in curtailing drug use in the Seychelles;

$\mathrm{b}$ describe and analyse the problem with the efforts and why they avail to nought;

c foresee what the situation will look like under the responsive approach (using Braithwaite's criteria); and

$\mathrm{d}$ discuss why the responsive approach will work better, thereby serving efficacy.

\section{B Current Efforts in Curtailing Drug Use in the Seychelles}

\section{The Misuse of Drugs Act (MODA), 2016}

The most protuberant effort in the curbing of drug use is irrevocably the introduction of the MODA and the Agency for the Prevention of Drug Abuse and Rehabilitation Agency Act, 2017. It is primarily through a reliance on these two laws that the government endeavours to curb drug use. The MODA presumes to curtail illegal drug use particularly by controlling the importation and trafficking of drugs; by making several presumptions as to who is to be perceived as having consumed drugs and delineating how the drug users are to be dealt with; and, in accordance with Section 8, by making the possession of drugs an offence. This means that despite the law drawing a distinction between a 'drug-dependent person' and a 'drug user', if either is found in possession of drugs in violation of the provisions of the Act, they may be penalized.

However, the law tends simultaneously to discourage conviction, thereby ensuring that a drug user takes responsibility for his actions without being stigmatized. Thus, where the person is convicted, the law is unhurried to impose a sentence unless the court considers there to be no suitable alternative. These efforts find expression in Section 39(3), and in many ways, mirror the Portuguese approach. ${ }^{11}$

Despite there appearing to be a number of alternatives to sentencing under Part 5 of the MODA, the predominant ruling by the courts is seemingly rather to give the drug user or the drug-dependent person an option to voluntarily pursue some type of treatment. ${ }^{12}$ The focus on the latter and the inclination towards the removal of associations of shame and disgrace were clearly demonstrated when, subsequent to the MODA, allowances for the reviewing of sentences of those convicted offenders were made via a tribunal set up in accordance with the Act.

10 ANU TV, 'The limits of responsive regulation' (November 2014) www.youtube.com/watch? v=etgNG8HIXRc <accessed 6 July 2020>.

11 Misuse of Drugs Act, Cap 39.

12 AFP News Agency, 'Seychelles: Addicts struggle as country battles heroin crisis|AFP' (February 2020) www.youtube.com/watch?v=xpPtlD4zpCE\# <accessed 3 August 2020〉. 
Out of the 210 cases brought forward for review, 158 prisoners were released and seven were sent for rehabilitation. ${ }^{13}$

\section{The Agency for the Prevention of Drug Abuse and Rehabilitation Act (APDAR Act), 2017}

The APDAR Act endeavours specifically to prevent drug abuse and is concerned with, as its long title suggests,

establish[ing] an Agency for coordinating the activities of various institutions and organisations concerned with the prevention of drug and alcohol abuse, treatment of drug users and rehabilitation of drug and alcohol addicts. ${ }^{14}$

The Act provides for the management and functions of all Detox Centres under the Ministry of Health and several other bodies established for similar purposes.

Dr. Low-Wah, a medical doctor, formally endorsed by the Health Care Agency as Chief Liaison Officer to APDAR, specifies how the units established under APDAR have in place programmes specific to their general objectives - the two most prominent being the high-threshold programme, which aims typically at helping their 150 patients enrolled thereunder to attain sobriety, and the lowthreshold programme, with some 1300 patients, which focuses on the abatement of the harmful consequences of drug use on a drug user or drug-dependent person and those around him. ${ }^{15}$

Whereas patients who are enrolled in the high-threshold service are given medication other than methadone (espranor) with an intention to be treated, those following the low-threshold programme are administered the relatively less costly methadone solely for the purpose of abating harm, infection, deviant behaviours and criminality by reducing cravings. Methadone thus serves as the most fitting solution for a government wanting to target, in an economic fashion, the larger drug user population. ${ }^{16}$

Contrary to the high-threshold programme, the low-threshold arm is generally less interventionist, endeavouring not to employ the assistance of psychologists and so on. It is within the lower threshold that most patients feature. ${ }^{17}$ The persons enrolled in the high-threshold programme, and who Dr. Low-Wah describes as typically more committed to the programme, may be relegated to the low-level threshold arm for failure to adhere to the compulsory treatments. The latter does not presume to compel the users to adhere to methadone treatment; thus, users follow the treatment purely out of choice. effect' (November 2016) www.seychellesnewsagency.com/articles/6286/Seychelles+judiciary + releases++drug+offenders+as+new+law+comes+into+effect <accessed 21 September 2020 .

15 Dr Winnie Low Wah, personal communication (1 August 2020).

16 Ibid.

17 Ibid 
Patients from the low- threshold programme are served their medication from a van before immediately being released back into the community. ${ }^{18}$

With regard to rehabilitation, the Centre Mont Royal Drug and Rehabilitation Centre, established in 1998, endeavours inter alia to

interrupt substance abuse and facilitate the maintenance of a sober lifestyle; facilitate the acquisition of life skills to enable the [patient] to successfully cope with the demands of life, [and to] foster personal growth. ${ }^{19}$

In a 2013 video addressed to the public, the then director of Centre Mont Royal, Robert Moumou, explained how a fire incident had left inutile the building within which the Centre conducted its affairs. Consequently, a 14-million Seychelles rupee $(£ 142,750)$ proposal for the reconstruction of the building was put forward. In the video in which Moumou appeals to the public to assist in raising funds for the building's reconstruction, he explains that a significant amount of capital concerning the project has already been raised. Moreover, Seychelles has been able to secure finances for a rehabilitation Centre from the United Arab Emirates (UAE) to be located on the main island of Mahé at Montagne Posée. ${ }^{20}$

\section{Obtaining External Assistance}

Endeavours towards the curtailment of drug use go beyond the aforementioned description. The Seychelles has reached out to neighbouring countries for assistance. Of notable significance is the collaboration of the Seychelles AntiNarcotics Bureau with that of Sri Lanka's (Police Narcotics Bureau) in a bid to rein back ongoing drug smuggling in the Indian Ocean. These efforts resulted in the arrest of a Sri Lankan national with family links in Seychelles pertaining to $231 \mathrm{~kg}$ of heroin ${ }^{21}$ and the discovery of "a racket [in which] heroin [was] brought to Sri Lanka by boat from Pakistan and [subsequently] taken to Seychelles..."22

Another similar and significant attempt on the part of the government involves President Faure's 2017 visit to Kenya to establish relations with President Kenyatta in an effort to combat narcotics. ${ }^{23}$ From this collaboration ensued the apprehension in 2017 by the Kenyan authorities of a couple, on the

18 Ibid.

19 Centre Mont Royal Drug and Rehabilitation Centre (2013) www.facebook.com/ CentreMontRoyalDrugAndAlcoholRehabilitationCentre/videos/575087832509657/ <accessed 3 August 2020>.

20 Betymie Bonnelame, 'UAE to fund, design \$ 3.6 million drug rehab centre in Seychelles' (January 2020) http://m.seychellesnewsagency.com/articles/12259/UAE+to+fund\%2C+design+ +.+million+drug+rehab+centre+in+Seychelles <accessed 21 August 2020 .

21 Sharon Ernesta, 'Sri Lanka Police in Seychelles to investigate drug trafficking' (March 2019) www.seychellesnewsagency.com/articles/10581/Sri+Lanka+police+in+Seychelles+to+investigate +drug+trafficking <accessed 3 August 2020>.

22 Ibid.

23 Seychelles Nation (December 2017), www.nation.sc/archive/257141/transforming-year-fordrug-enforcement-in-seychelles <accessed 6 July 2020>. 
border between Kenya and Tanzania, who were being sought out by the NDEA in connection with a significant amount of heroin seized by it in October 2014. ${ }^{24}$

\section{Problem with the Current Efforts}

\section{Problems with Efforts under MODA}

MODA makes the trafficking and importation of drugs an offence. The responsibility to keep drugs from coming onto Seychelles' shores rests with the police. Seychelles is an archipelago of 115 islands, but the majority of drugs are present on the three main islands; Mahé being where heroin usage is most rife. Although Saigal argues that Seychelles' porous borders make it easy for drugs to find their way into the country, it may be beyond deductive reasoning as to how a 157.3-km island cannot be monitored and drug traffickers tracked down through the interception of telecommunication, surveillance by drones and telescopic cameras and by the adducing of evidence by the very willing population inclined to 'rat' each other out. This leads one to conclude that perhaps there is a blatant unwillingness on the part of the government to actively target drug traffickers.

However, Compol Labonte attempts to put things into perspective. In a 2017 interview with the Seychelles News Agency wherein he answers the question as to why NDEA opts to rather target small-time drug dealers and victims of drug abuse as opposed to pursuing large importers with huge amounts of resources, Labonte expounds on the legal impediments in targeting the 'big fish', in that it is often difficult to adduce enough evidence for a solid case. The courts do not rely on presumptions and inference, he says, but on evidence which requires time for amassing. Intensive surveillance is also required and there needs to be established a connection between the suspect and the drugs. He goes on to explain how the 'big fish' is oftentimes an elusive financial backer who does not physically handle the merchandise. ${ }^{25}$ Either way, be it for an inability to actively target the big fish for the reasons that Labonte cites or otherwise, drug traffickers are seldom apprehended. ${ }^{26}$ In fact, concluding any drug case under MODA has proven challenging as some 478 cases, predominantly criminal, remain pending in the Supreme Court. ${ }^{27}$

The presumption of drug use is found in Section 24 of the Act, in that a person is presumed a drug user where a controlled drug is found in his urine or blood following a test carried out under the Act, the Road Transport Act or the Criminal Procedure Code until the person proves the contrary. ${ }^{28}$ The Act delineates a number of instances whereby a person is to be presumed a drug user, none of

24 Ibid

25 Jamila Figaro and Betymie Bonnelame, 'Seychelles' drug agency chief: Target 'big fish' with surveillance, intelligence work' (April 2017) www.seychellesnewsagency.com/articles/7132/ Seychelles\%27+drug+agency+chief+Target+\%27big+fish\%27+with+surveillance\%2C +intelligence+work <accessed 6 July 2020>.

26 Ibid.

27 Statistics from Legal Affairs, Office of the Chief Justice.

28 ANU TV, note 10. 
which include them fumbling in bins, testimonials from their family, able-bodied men and women begging for money and selling stolen goods on the side of the road and so on. These aberrant activities have all been recognized by doctors, the police and members of the community as those characteristic of drug users. However, the government has been reluctant to 'call a spade a spade'.

A government seeking a positive change and endeavouring to rescue those who misuse drugs cannot afford to sugarcoat the reality. It is imperative that the law is as raw as the situation. Otherwise, if we turn a blind eye to the reality of who the targets are, how can we be of any assistance to them? There needs to be a willingness to identify the drug users even at the time they commit minor offences that are too often overlooked. It is of utmost importance that we graduate from the notion of being driven to making a presumption of drug use merely subsequent to the taking of blood samples and so on, to more easily visible indicators. In all fairness, blood and urine samples are not easily attainable.

We cannot presume to target the drug user only when he or she has committed a more serious offence. He or she requires help before being driven to violate societal rules that carry greater punishments. Should the presumption be inaccurate, it can always be rebutted. The MODA, in trying to discourage conviction, ensures that a drug user is able to take responsibility for his actions without being stigmatized. Thus, although there appears to be a number of alternatives to sentencing in the 2016 Act, the predominant ruling of the courts is giving the drug user or the drug-dependent person an option to enter a programme or go to rehab. However, this can prove to have some dire consequences.

The liberal approach of going easy on the drug users and leaving them with an option may have them truly believing that they are a victim. This could greatly affect their desire to take responsibility for their actions towards their family and the community in general. In an interview with family members of those addicted to drugs, one person described how her parents never got to enjoy their retirement. She likened their predicament to that of prisoners in their own home. Another explained how she had to sleep with one eye open. The majority of persons I spoke to described how their belongings were constantly being sold and how they were often subject to both physical and verbal abuse. Thus, the inculcation of a victim mentality into the drug users may have the undesirable effect of fuelling their bad behaviour and robbing the drug users of the understanding that, in as much as the government has a responsibility towards them, they too have a responsibility towards their family and the community at large.

The efforts that the Tribunal has made concerning the reviewing of sentences subsequent to the enactment of the MODA and the release of a number of offenders could prove detrimental to society. Although Romano Songor, from the police department, explains that there has not been a formal survey to prove the following, the police department has observed that repeat offences pertaining especially to thefts, robberies and related offences are more often committed by 
drug users. On relapse, statistics show that offences against tourists are rather rampant. ${ }^{29}$

From what Dr. Low-Wah suggests concerning the inability of a drug user to stay committed to the programme, it is understandable how a drug-driven offender would resort to theft to feed his habit subsequent to a failure to adhere to a programme. In fact, according to statistics obtained from the police department, with regard to offences committed against a person, 749 cases were recorded in $2019 .{ }^{30}$ With regard to the number of thefts, a total of 1156 cases were recorded in that same year. ${ }^{31}$ These are rather alarming statistics for a population of only 98,347 people.

\section{Problems with Efforts under APDAR}

It appears that the efforts in one of the two most prominent programmes - the low threshold - does not necessarily help the ones who most need assistance. The fact that there are more patients on the low-threshold programme but are being given less interventionist care by the Agency is a cause for concern.

Dr. Low-Wah explains that patients enrolled in the low-level programme are less committed to sorting themselves out. ${ }^{32}$ However, this means that the core issues will never be dealt with through therapy and whatever else is needed to dig into the fundamentals of each addict's issues. So, there is no real effort to target the weaker willed drug users and the ones who certainly require the most assistance. Accordingly, the Agency, in this case, can be perceived as merely covering the wounds as opposed to actively medicating and curing them.

The situation is exacerbated when those persons who are part of either the low- or high-threshold programme are given their medication before being sent right back to the very society which, in the first instance, motivated their misuse of drug habits. Those enrolled in the low-threshold programme are generally perceived as weaker willed and cannot be expected to endure without interventionist efforts and without mechanisms to guide them through societal pressures likely to cause one to buckle.

An interviewee mother of a young man from the Seychelles suffering from addiction expounded on how drug addicts find themselves caught in a vicious cycle of going through the methadone treatment, drinking, taking drugs before reverting to methadone. It is no wonder that $90 \%$ of the people whom I interviewed and who have a member of their family addicted to narcotics believe that the system which is in place is either not really effective or not effective at all. ${ }^{33}$ In fact, Dr. Low-Wah sighed her discouragement when she spoke of the extensive number of repeat patients who frequent the programme. The former director of the Centre Mont Royal, Robert Moumou, who has since resigned from

29 Romano Songor, Deputy Commissioner of Specialized Operations Anti-Narcotics Bureau, personal communication (16 July 2020).

30 Ibid.

31 Ibid.

32 Prevention of Drug Abuse and Rehabilitation Agency Act 2017, note 14.

33 Personal survey. 
his post, explained in an interview how he managed to raise some 2 million Seychelles rupees $(£ 85,913)$ for the restoration of the rehabilitation Centre in the first year after a fundraising campaign commenced.

However, the fundraising project ended on the grounds that the rebuilding project fell under the purview of the government with the Centre being government property, and as such, it was for the government to rebuild the Centre. Unfortunately, the Centre, which burnt down in 2011, has to date not been replaced. Thus, although the Act suggests that the Centre has moved under APDAR, it is no longer functional. According to Moumou, APDAR had plans of building a rehabilitation centre at Cap Ternay, which, to date, has not materialized.

Moumou stated that all non-scientific and non-medicine approaches in the field have been removed, thereby undermining the previous emphasis placed on rehabilitation centres. "The physical aspect of addiction, which involves stabilising the patient from withdrawal, accounts for one quarter of the treatment", he said. "The psychological aspect is the real treatment, that is training the addict to be sober for life. Unfortunately, they have opted for substitution therapy instead." 34

Thus, as Moumou suggests, the primary issue is the lack of psychological intervention. ${ }^{35}$ In fact, Dr. Jhanjee from the Department of Psychiatry at the National Drug Dependence Treatment Centre in India expounds on the literature review which has been undertaken using various electronic databases pertaining to psychosocial issues in addictive disorders and guidelines on this topic. The evidence base cited comprised findings in which persons exposed to these psychosocial interventions had much better substance use outcomes either towards the end of the treatment phase or at follow-up.

Various psychosocial treatments or interventions for substance use disorders, including cognitive behavioural therapy and contingency management, are 'evidence based'. ${ }^{36}$ It is therefore apt for psychological interventions to feature as an integral part of the treatment regimen and efforts ought to be made to incorporate evidence-based interventions in every substance use disorder treatment programme. ${ }^{37}$ Whereas Dr. Low-Wah explains that the rebuilding of the Centre in situ to be undertaken by the government ensures the patients are close to their family and ensures easier reintegration into society, I subscribe to the view that complete seclusion is perhaps the best way forward, as being naturally weak-willed persons, drug users are inclined to relapsing if exposed to the very environment that rendered them in the predicament they find themselves in. Thus, despite having secured finances for another rehabilitation Centre, the project which is to occur at a different location (Montagne Posée) on the main island is still of no consequence, as the proposal is to have it built where

Robert Moumou, former director of Mont Royal Centre, personal communication (5 July 2020). Ibid.

Sonali Jhanjee, 'Evidence based psychosocial interventions in substance use' (2014) www.ncbi.nlm.nih.gov/pmc/articles/PMC4031575/ <accessed 5 July 2020〉. 
narcotics are easily accessible. The release of users into society ought to occur at some point, but only once the drug user proves himself adequately resilient to societal pressure.

These sentiments are not unfounded, as according to the Canadian Centre for Addiction website,

One of the most important benefits of rehab away from home is that the drug addict gets away from all the harmful influences that could lead to a relapse. Stressful situations, pressure from friends and even old habits can have a negative impact on [his] recovery. ${ }^{38}$

A fresh environment allows one time to concentrate on what really counts, which is one's recovery, and puts one into the mindset towards getting clean. ${ }^{39}$ Unfortunately, an away-from-home centre currently does not exist.

\section{Problems with Obtaining External Assistance}

Although I do not discount the involvement of other countries which assist the Seychelles in its drug curtailment efforts, the two main concerns are, first, that these efforts focus on drug traffickers, who Songor himself reckons are extremely elusive. Moreover, once apprehended, their outside counterparts are most undoubtedly still trafficking. Those traffickers who eventually appear before the court face sustained court battles lasting many years, while drugs are still in circulation and drug users still struggle to get their lives together.

Second, there arises the question as to whether the countries with which the Seychelles has established relations are in fact capable of effectively rendering a service to another. It is imperative that assisting countries meet certain requirements. Chief Officer Liam Quinn suggests that international cooperation is crucial to the successful management and controlling of drug distribution and importation, but this is best achieved by internationally recognized bodies that have the network, the funds and the credibility to enable and facilitate such cooperation. ${ }^{40}$

Whether the countries that the Seychelles has chosen to engage with meet these requirements is questionable. Although the efforts may have yielded some benefits, Seychelles still ranks number one globally per capita in terms of countries plagued by heroin. ${ }^{41}$ Perhaps poor partnership decisions could be a contributing factor. It is commonly understood, for instance, that Sri Lanka's drug abuse dilemma has huge economic and social implications on the country of approximately 21 million people with a minimum wage of a measly USD2.50 canadiancentreforaddictions.org/benefits-rehab-away-home/ <accessed 5 July 2020〉.

39 Ibid.

40 Liam Quinn, 'Maritime drug enforcement capacity skills-equipment-laws-detectioninvestigation-intelligence-political will' www.southernroute.org/download/(04)\%20SEY CHELLES\%20Presentation.pdf <accessed 5 April 2020>.

41 Kanika Saigal, 'Why Seychelles has world's worst heroin problem' (November 2019) www.bbc.com/news/world-africa-50488877 <accessed 21 September 2020>. 
(£1.94) per day. Sri Lanka’s daily consumption of drugs totals to nearly USD3 (£2.32) million, which places a colossal burden on the economy and the finances of individual households. Moreover, Sri Lanka lacks in financial and human resources, in capacity building and in officers trained to counter the drug trade. ${ }^{42}$

Kenya too has been criticized for doing the least possible in curbing drug use within the country. Other than its anti-narcotic laws, which provide for life imprisonment, the USD

$10,000(£ 7,745.95)$ in fines and the seizure of ill-gained wealth, insufficient action has been taken. As a result of its lack of ability and its lethargy in taking action in the earlier years, Kenya now suffers the consequences.

The Bureau of International Narcotics and Law Enforcement Affairs - in its 2016 International Narcotics Control Strategy Report - remarks,

Stemming the flow of illicit drugs is a challenge for Kenyan authorities. Drug trafficking organisations take advantage of corruption within the Kenyan government and business community, and proceeds from drug trafficking contribute to the corruption of Kenyan institutions. High level prosecutions or large seizures remain infrequent. ${ }^{43}$

It is thus fair to say that although the establishing of relations for the purpose of keeping drug use at bay may have been done with the purest of intentions, the partnering countries leave a lot to be desired as they have significant problems of their own. This in turn can affect the quality of service they render and the extent to which they can commit themselves to helping others.

\section{Possible Solution}

Seychelles, in trying to achieve lower drug consumption, replaced a punitive approach for a more restorative one. However, although the aproach has proven rather efficient in Portugal, its employment in the Seychelles has not yielded similar results. This is perhaps due to a lack of clarity, organization and understanding of the Seychelles' context. Braithwaite offers us structure and clarity through his responsive regulation in the form of unambiguous escalating efforts reflected in the pyramid of criteria (Figure 1), which starts off by treating the drug user or drug-driven offender as having a disease and later penalizing him if he persists in his abhorrent ways. It is precisely this clever combination of both treatment and punishment that makes Braithwaite's model different from the

42 Thee Editors, 'How Sri Lanka, a growing drug trafficking hub is fighting drug abuse at home' (February 2018) www.worldpoliticsreview.com/insights/24190/how-sri-lanka-a-growing-drugtrafficking-hub-is-fighting-drug-abuse-at-home <accessed 5 August 2020 >.

43 Ken Opala, 'War on drugs: Kenya, the forgotten hotspot of the heroin trade' (April 2017) www.theelephant.info/features/2017/04/07/war-on-drugs-kenya-the-forgotten-hotspot-of-theheroin-trade/ <accesed 5 August 2020>. 
approach currently employed. The approach also offers de-escalation of the pyramid whenever the circumstances so warrant.

Besides the aforementioned, Braithwaite's pyramid is promising in that, being an expression of responsive regulation, it is based on the principle that regulators ought to be responsive to the culture, conduct and context of those they seek to regulate when deciding whether a more or less interventionist response is needed. ${ }^{44}$ In other words, it encourages practicality, an aspect which the Seychelles failed to take into consideration with regard to its efforts. It is not apt that our laws and efforts are based on pre-written laws and transplanted into our own jurisdictions without taking into account context and culture.

Kim Zimmerman suggests that "Culture is the characteristic and knowledge of a particular group of people, encompassing language, religion, cuisine, social habits, music and arts" ${ }^{45}$ An understanding of one's culture is key to change. One thing that authorities ought to appreciate is that each country is sovereign, and as such, a government ought to make a conscientious decision to rule its country in accordance with what it knows works for the people, what drives its people and, thereafter, respond accordingly. The responsive approach strongly promotes this ideology. If this system is to be successful, the drug users and drug-dependent persons ought to be identified on the basis of the new presumptions suggested under Section 3 of this article. This is essentially what would also be typical of context. The target should therefore be clear. On committing an offence which would otherwise warrant a punishment under the law, for example, loitering, selling stolen goods by the side of the road, begging, theft, the person will either admit to being a drug addict, thereby immediately commencing the path laid out by Braithwaite, or otherwise be arrested and sentenced. The pyramid will undoubtedly apply to anyone who is found in possession of or who has consumed drugs above the prescribed limits as these too are punishable offences.

This approach demands that once a user signs to opt out of being arrested and undertakes the programme, he would have signed away his freedom to bow out and thus be compelled to follow through until fruition. Compelling a drug addict to follow this programme regardless of a change in sentiments at any stage of the pyramid should not be perceived as a malicious infringement of his fundamental right to freedom, for the reason that, first, he committed an offence and contracted rather to pursue the process under the pyramid, and second, a person who has a drug addiction is perceived as having a mental disease which needs immediate attention.

Addiction, clinically referred to as a substance use disorder, is a complex disease of the brain and body that involves compulsive use of one or more substances despite serious health and social consequences. Addiction disrupts

44 Charlotte Wood et al., Occasional paper, June 2020, Australian National University ANU.

45 Kim Anne Zimmermann, 'What is culture?' (July 2017) www.livescience.com/21478-what-isculture-definition-of-culture.html <accessed 3 August 2020〉. 
regions of the brain that are responsible for reward, motivation, learning, judgment and memory. ${ }^{46}$

In the most chronic form of the disease, a severe substance use disorder can cause a person to stop caring about his own or others' well-being or survival. ${ }^{47}$ The rationale behind compelling treatment on a drug addict is comparable therefore with other mental illnesses, concerning which the person in fact oftentimes has no say when he is admitted into psychiatric care on the premise that he is a danger to himself and to society. According to the U.S. Library of Medicine, opioid addiction can cause life-threatening health problems, including overdose, which either slows down or stops breathing, leading possibly to unconsciousness or death. ${ }^{48}$

The question is, can we really leave a decision to bow out of the journey towards sobriety in the hands of a person whose judgment is clearly impaired? It is the government's responsibility therefore to protect both the addict and the community by compelling the drug user, once identified, to see the process through. The compelling of the user to follow through is also contextual, and it is another way in which this approach differs from the current running.

\section{Capacity Building}

When one speaks of capacity building, organizations come to mind. However, the building or expanding of one's personal capacity far exceeds an organizational context. According to the definition of the United Nations Development Programme (UNDP), at an individual level capacity building refers to the process of changing attitudes and behaviours, imparting knowledge and developing skills while maximizing the benefits of participation, knowledge exchange and ownership. ${ }^{49}$

Capacity building features in the first tier of the pyramid following the agreement to the alternative to an arrest. The drug user at this stage has admitted to have been under the influence and is now required to attend a number of sessions pertaining to building his personal capacity if the drug confirmatory tests prove positive; otherwise, a conviction awaits. Latumahina suggests that in expanding one's capacity, one is able to accomplish and handle that which one was formally unable to, thereby potentially becoming a different person. ${ }^{50}$

Partnership Staff, 'Is addiction a disease' (July 2020) https://drugfree.org/article/is-addiction-adisease/\# <accessed 3 August 2020>.

47 Ibid.

48 U.S National Library of Medicine, 'Opioid addiction', https://ghr.nlm.nih.gov/condition/opioidaddiction <accessed 5 August 2020>.

49 'Lear, Capacity building: Is it only a matter of training?' www.learlab.com/insights/capacitybuilding-is-it-only-a-matter-oftraining/\#: :text=At\%20the\%20individual\%20level\%2C \%20capacity,participation\%2C\%20knowledge\%20exchange\%20and\%20ownership <accessed 3 April 2020>.

50 Donald Latumahina, '8 tips to expand your personal capacity' (August 2010) www.lifeoptimizer.org/2010/08/06/expand-your-personal-capacity/ <accessed 3 August 2020 . 


\section{Restorative}

Whereas the first tier is more concerned with imparting information and trying to make the drug users understand who they are, where they are at and where they can or ought to be in life, thereby stirring within them the desire to do better by themselves, this tier tends rather to be more influential and vigorous as it comes after the drug user persists in consuming drugs and behaving defiantly. At the restorative tier, the user is still perceived as a victim of a disease and should be treated as such.

It therefore involves a more active participation of the drug user and mental health specialists. Thus, it is at this stage that more extensive support is rendered after he, subsequent to self-examination at the previous tier, failed to maintain sobriety for want of a more active and structured support. Other than physical restoration, this tier also leans on restoring the drug user's values within himself, which would ultimately improve the relationship with his family, others around him and the community as a whole. This in reality is what rehabilitation necessitates and thus ought to be directed towards all drug users. It is the act of restoring to a condition of good health, ability to work or the like. ${ }^{51}$ Treatment enables people to counteract addiction's disruptive effects on their brain and behaviour and regain control of their lives. ${ }^{52}$

Clearly, there are two main aspects with regard to restoration. First, is the administration of medications and the use of devices to treat addictions and to help the addicts stay in treatment, and second, is behavioural therapy. Thus, in treating withdrawals, medications and devices can alleviate symptoms, making the transition to sobriety easier as patients who stop taking drugs habitually experience both physical and emotional symptoms which include mental health conditions.

With regard to staying in treatment, medications and mobile applications help the brain to gradually adapt to a lack of narcotics. These treatments over time prevent drug cravings and calm the body systems. This allows patients to focus on counselling and other psychotherapies related to their treatment. ${ }^{53}$ Medicaments work in conjunction with the second aspect of restoration, which is behavioural therapy. Behavioural therapy is perhaps what is most commonly used during substance rehabilitation. The following are a variety of effective techniques adapted to a general behavioural therapeutic approach:

- Cognitive behavioural therapy (CBT) is therapy concerning which people learn to recognize and change their maladaptive behaviours. This helps drug users cope with and identify risky situations and what to do about them, and with preventing relapse. CBT can be used to treat co-occurring mental or physical health disorders as well.

- Contingency management (CM) is thought to be effective in treating inter alia opioids and used to encourage or reinforce sobriety. This method

51 Dictionary.com, www.dictionary.com/browse/rehabilitate <accessed 24 July 2020 .

52 NIDA, 'Treatment and recovery' (10 July 2020) www.drugabuse.gov/publications/drugs-brainsbehavior-science-addiction/treatment-recovery <accessed 3 August 2020〉.

53 Ibid. 
provides material rewards as motivation for maintaining sobriety. CM is catalyst in the reduction in dropping out and relapse. ${ }^{54}$ To be sober in society means to be clear-minded and free from inebriation. Hence, the idiom 'as sober as a judge'. ${ }^{55}$ Thus, sobriety may be construed as a virtue. What is interesting is that, under $\mathrm{CM}$, material reward is given, which is a great way to show the drug user that he is actually moving forward, and this can greatly boost his confidence to press on in his restoration process. Psychologists describe this as positive reinforcement, which is a method predominantly used in children and is described as one of the most effective behaviour modification techniques. Positive reinforcement can also be an effective way to encourage and motivate one to be responsible. ${ }^{56}$

- Motivational interviewing is a method of resolving ambivalence in recovering individuals to allow them to embrace their treatment efforts to best change their problematic substance use behaviour.

- Dialectal behavioural therapy mainly focuses on treating severe personality disorders. It works to reduce cravings, to help patients avoid situations or opportunities to relapse, to assist in giving up actions that reinforce substance use and to help users learn healthy coping skills.

- Rational emotive behaviour therapy helps patients understand their own thoughts and then helps to develop better habits and thinking in more positive and rational ways and gain healthier emotions. 2 The base for this therapy is the idea that rational thinking comes from within; external situations are not what gives one the feeling of happiness or unhappiness.

- Matrix Model employs a combination of various therapeutic techniques and was originally developed for the treatment of individuals with stimulant addictions. Against this backdrop of various techniques, therapists focus on rewarding good behaviours and teaching patients to obtain self-esteem, dignity and self-worth.

- Twelve-step facilitation therapy aims to promote continued abstinence by engaging people in recovery with twelve-step peer support groups. ${ }^{57}$

As opposed to trying to address only the symptoms, the various techniques described seemingly target the core issues by employing specialist interventions. It is imperative that the programme extends to all drug users and not only to those who, the experts suggest, are more committed. In fact, Dr. Low-Wah suggests that most addicts are unaware as to the programme under which they have been registered. ${ }^{58}$ Therefore, one wonders to what extent they were given

54 Leah Miller, 'Types of therapy used in treatment' (October 2019) https:// americanaddictioncenters.org/therapy-treatment <accessed 3 August 2020>.

55 Dictionary.com, www.dictionary.com/browse/sober-as-a-judge\#: :text=explore\%20dictio nary-,sober\%20as\%20a\%20judge,was\%20first\%20recorded\%20in\%201694 <accessed 3 August 2020>.

56 Amy Morin, 'Using positive reinforcement to improve your child's behaviour' (May 2020) www.verywellfamily.com/positive-reinforcement-child-behavior-1094889 <accessed 3 August 2020 >.

57 NIDA, note 52.

58 Prevention of Drug, note 14. 
the opportunity to express a desire to be enrolled on the high-threshold programme or otherwise. Attacking core issues in all addicts will mean more of a long-term result, which is why at this stage, all users will be afforded the aforementioned treatments.

\section{Deterrence}

Deterrence has been defined as the act of discouraging an action or event through instilling within a person doubt or fear of the consequences. ${ }^{59}$ Whereas penal provisions have its benefits, what is often unclear to the government is whether it should treat as an offence, bad behaviour associated with drug use or simply consider it a consequence of a disease. As mentioned, Braithwaite's approach caters to both treating the drug user and taking him to task at the point where he becomes a persistent offender, who either blatantly refuses to continue rehabilitation and to abide by the programme or completes rehabilitation but relapses into drugs and his abhorrent ways.

Since the treatment tiers are now spent, this tier is where the drug user/ offender starts taking responsibility for his actions. Thus, if at any time either after or during rehabilitation, the drug user persists in consuming narcotics, stealing, being idle, harassing others and putting pressure on his family and the community as a result of his inability to remain sober, he will face threats of incapacitation. The law ought to be clear about what the penalty for violence, theft, abuse and idleness occasioned by drug abuse carries, so that if there is a failure on the part of the drug user to follow through the different steps of the pyramid, his deterrent would be the fear of whatever punishment his breach of the law warrants.

According to the International Narcotics Control Board, the deterrent effect of law enforcement efforts influences the demand for illicit drugs. The risk of penal sanctions may act as a deterrent to members of the general population who have never abused drugs. Though the risk of such sanctions does not, in all cases, deter addicts, who require drugs regardless of the consequences, the impact of law enforcement efforts on supply may force addicts to take advantage of treatment and psychosocial interventions. ${ }^{60}$

It is thus at this point of the pyramid that de-escalation of the pyramid is more likely. Once a user realizes that punishment is imminent, he, knowing full well that his addiction is still rather raw and that there is a possibility of his relapsing and reverting to his deviant ways, would opt rather to repeat the previous restorative tier of the pyramid. The deterrent tier lies parallel to what is termed a 'rational actor' in Figure 1, for it is on this tier that the drug user is expected to make a decision based on logic: he either galvanizes himself into going back to the restoration tier to help cure his disease, thus reducing the chances of lapsing into his bad habits, or risks incapacitation.

59 Lexico, 'Deterrence' www.lexico.com/en/definition/deterrence <accessed 3 August 2020>.

60 United Nations, Report of the International Narcotics Control Board for 2004, www.incb.org/ pdf/e/ar/2004/incb_report_2004_full.pdf <accessed 15 November 2010>. 


\section{Incapacitation(Incompetent/Irrational Actor)}

If all the tiers of the pyramid have been exhausted and the drug user, after going through the tiers, proves to be irrational and unwilling to receive the support that is rendered via the pyramid, he must be held accountable for his actions. This is because the stages during which we sympathize with the drug user as a victim of a mental disease have now passed. The refusal on his part to pursue his sobriety before his reintegration into society is telling of his sentiments regarding his duty to his family and the rest of the population. By having at the apex of the pyramid the incapacitation tier, the country affirms its obligations towards the user's family members and the community, which is to keep everybody safe.

\section{E Analysis: Why the Responsive Approach Will Work Better}

The previous section of this article aimed to show how drug use can be regulated through a cohesive effort reflected in a number of criteria featured in Braithwaite's pyramid in contrast to utilizing the 'benign big gun'. The pyramid is an example of responsive regulation, which employs various actors, so that if one actor fails, another takes over. The combination of treatment and incapacitation of the user means that both he and the community benefit. This section will show why Braithwaite's method is suitable for the Seychelles and how the effective curtailment of drug use in fact transcends legislation. It is for the drafter to identify the limits in legislation and advise the government of how best to achieve efficacious regulation.

\section{The Right Presumption for a Clear Target}

Given that drug traffickers are seldom apprehended and that drug trafficking cases before the courts drag over long periods of time, a different target is on offer. Braithwaite's pyramid allows us liberty to choose whichever target is deemed fit in the Seychelles' context - the most favourable and palpable being the drug user himself. Without a clear target the efforts are useless. By making more practical presumptions as to who the drug users are, targeting is made easier. An amendment to the Act will be warranted to make clear who the targets are, so that a lawful obligation can thereafter be placed on the drug user when he embarks on the capacity building and restorative journey once he is apprehended. Presumptions will thus include expressive behaviours which the public, the police and doctors suppose are associated with drug use.

This means that the relevant actors together with the drafters from the Office of the Attorney General will be engaged in a series of serious discussions concerning what exactly constitutes visible signs of drug use in persons on the street. The outcome of these discussions will then be imported into the law, forming presumptions subject to rebuttals whenever persuasive evidence to the contrary is presented. ${ }^{61}$ Presumptions as such are likely to ensure a fast clean-up

61 Duhaim.org, 'Duhaimes Law Dictionary' www.duhaime.org/LegalDictionary/R/ RebuttablePresumption.aspx <accessed 21 September 2020〉. 
of the streets, giving effect to the ancient proverb that it is 'better [to be] safe than sorry'. The onus will rest on the drug user to prove his sobriety.

\section{The Learning Citizen}

The desired result for employing this approach is primarily to restore the user's self-confidence to the point that he no longer finds his identity in opioids. This is achieved first by helping him build his personal capacity. If we had to unravel UNDP's definition of capacity building and apply it to a drug user, we find that, first, the recognition of a change in attitude hints highly on the necessity for mental healthcare specialists and possibly religious interventions. According to Cherry, in psychology, an attitude implies a set of emotions, beliefs and behaviours towards a specific object, person, thing or event. Attitudes often develop because of an experience or upbringing and potentially have a powerful influence over behaviour. While attitudes are enduring, they can be altered. Cherry explains how attitudes are shaped by various factors such as experience, social factors and learning. ${ }^{62}$ It is for the mental healthcare specialists to understand - through a plethora of sessions and continuous engagement and activities - how each of these factors influences the attitude of each drug user. It is only through an understanding of the reason why the attitude came about can we determine how it can be changed through a renewing of the mind.

According to the American Psychological Association, attitudes, while having a powerful effect on behaviour, are not set in stone. The same influences that lead to attitude formation can also create attitude change. ${ }^{63}$ The three components of attitude need to be understood if a change is to be expected. These are as follows:

a The cognitive component, which entails the drug user's thoughts and beliefs about the substance

b The affective component, which is how drugs make the drug user feel

c The behavioural component, which is how the attitude influences the drug user's behaviour ${ }^{64}$

Thus, if the drug addict believes in his mind that consumption of the substance has no consequence for anyone else but himself and that he cannot find an identity outside of narcotics, it is up to the mental healthcare specialists, his spiritual leader and other relevant actors to help him break away from this mentality so that he understands that his attitude is what influences his behaviour towards himself and others and which, in turn, hurts himself and others around him.

Should the mental healthcare specialists and other actors succeed in assisting the drug user understand the former, and he is consequently able to change his ways, then he would be on his way to becoming a 'better person'. Thus, the capacity-building tier of the pyramid is extremely relevant in our efforts to

62 Kendra Cherry, 'Attitudes and behaviour in psychology' (May 2020) www.verywellmind.com/ attitudes-how-they-form-change-shape-behavior-2795897 <accessed 3 August 2020〉.

63 American Psychological Association, 'Important issues or topic in psychology' (2009) www.apa.org/pi/aids/resources/education/attitude-change <accessed 3 August 2020〉. 
bestow upon drug users and drug-dependent persons information which can serve to empower them.

Information provided to users in this tier ought to allow them to understand who they are and give them a reality check as to the predicament they find themselves in, understand where they wish to be in the future and how exactly they are going to achieve their desired objective, all the while taking into account their culture, their religious orientation, the circumstances that gave rise to the drug use and how they behave and react in specific situations. It is for this reason that, in the illustrated pyramid, the learning citizen lies parallel to this tier. It is at this stage of the pyramid that profuse edification is rendered. Doctors are often perceived as being trustworthy, reliable and capable of holding erudite discussions with the targets. They too are crucial actors in this process. It is imperative thus that the former deliver information based on World Health Organization publications on the consequences of narcotics, in an endeavour to set a suitable tone and create the right context.

These discussions will extensively include how drug users tend to have high human immunodeficiency virus (HIV) infection rates (primarily because of unsafe needling) and increased rates of tuberculosis infection, regardless of their HIV status. $^{65}$

Information such as these ought to hopefully dissuade the drug user by showing him how addiction is capable of ruining his life and destroying anything that he may have built for himself, which runs contrary to him building his capacity. It should push him to make positive changes. Personal development skills are skills an individual requires to enable him to set personal goals and to achieve personal empowerment. A user can build a strong and effective skill set through personal development and this will help him make relevant choices and decisions in the future. ${ }^{66}$ The skilful tend to feel needed, knowing they have something to offer. This can greatly boost their self-confidence to set goals for themselves. A clear goal which one is determined to meet means that one is willing to put aside any habit that could potentially hamper its attainment.

According to Jessica Wishart, seeking out experts could help the target learn what he needs to know to master skills and capabilities. Drug addicts at this tier ought therefore be afforded the right resources to help them get where they want to go. ${ }^{67}$ Thus, where a user is able - through the help of a coach - to find and develop his talents, this could give him a sense of self-worth and a sense of obligation to himself to keep sober in an effort to walk within his purpose and to break away from the widespread fallacy daringly expressed by a recovering addict,

65 World Health Organisation, 'Management of substance abuse' (2008) www.who.int/ substance_abuse/publications/drugs/en/\#: :text=Drug\%20users\%20have\%20high\%20rates,TB \%20infection\%20to\%20TB\%20disease <accessed 3 August 2020>.

66 (C) SkillsYouNeed (2017) www.skillsyouneed.com/ips/barriers-communication.html.

67 Jessica Wishart, 'Personal capacity building: 6 tips to double it' (January 2020) www.rhythmsystems.com/blog/bid/155390/6-tips-to-double-your-personal-capacity <accessed 3 August 2020 >. 
that is, "We're a small island in the middle of the ocean. What else is there to do here?" 68

The reason why context and culture are relevant here is because, through an understanding of what rings true to the drug user, the experts are able to help him decide what drives him to be a better person, what it is he ought to pursue and develop his skills on this basis. This whole endeavour in building capacity thus involves a concerted effort and a very interactive process by various actors. Past drug users ought to be able to share their testimony and their journey to provide hope and encouragement to the current users, guiding them to rise above their circumstances.

Shared experiences are always well received as open dialogue and positive interactions are all essential elements for effective intervention. People are more inclined to listen and learn from those with similar experiences as opposed to being talked down to by those with no inkling as to what it means to be an addict. At this tier, addicts will learn to

[take] responsibility for [their] thoughts, actions, and life [which] can feel challenging. It requires a willingness to learn from [their] mistakes, to own [their] successes and failures, and to stop blaming others for [their predicament]. ${ }^{69}$ These interactions will allow the drug user to understand why it is vital to take ownership of his life. Ownership will help build his character, grit, and self-respect; all key characteristics that build capacity. It will allow the drug user to proactively create a fulfilling, meaningful, and healthy life where he decides how to respond to his circumstances with accountability and fortitude. Once he understands that the quality of his life is largely influenced by his mindset, focus, and actions, he will have the freedom to choose his response. ${ }^{70}$

\section{The Virtuous Citizen}

The restorative tier of the pyramid is where the drug user's values are restored. While having virtues could primarily benefit the user, a person exhibiting virtues serves the community as and when he becomes cognizant of his behaviour towards others. The restorative tier occurs subsequent to an inability on the part of the user to straighten himself out at the first tier. Although it is possible for a casual user to overcome an addiction at the first stage, for an avid user, the restoration tier is anticipated. Unlike the current state of affairs, restoration

AFP, 'Addiction in paradise: Seychelles battles heroin crisis' (February 2020) www.seychellesnewsagency.com/articles/12463/Addiction+in+paradise+Seychelles+battles +heroin+crisis <accessed 21 September 2020>.

69 Mind Tools, 'Helping people take responsibility' www.mindtools.com/pages/article/takingresponsibility.htm <accessed 3 August 2020>.

70 Michelle Rees, 'How to take ownership of your life (and get everything you want)' www.wholelifechallenge.com/how-to-take-ownership-of-your-life-and-get-everything-you-want/ \#: :text=Taking\%20responsibility\%20for\%20your\%20thoughts,grit\%2C\%20and\%20self \%2Drespect <accessed 3 August 2020>. 
under the pyramid requires all drug addicts, whether perceived as more committed or not, to be given an opportunity to shake the habit not just through a substitution method but through proper psychological and spiritual interventions, as our context requires. Interventions at this criterion are extensive. Since the responsive approach also considers religion, the drug users may seek the type of spiritual guidance that they themselves trust can accelerate their journey to sobriety.

Being a predominantly Christian nation, the users' values are founded on Christianity. The fact that $100 \%$ of interviewees believe that spirituality plays a key role in sobriety in the Seychelles context, despite they themselves showing no particular inclinations towards religion, is telling of what drives the nation. Indeed, plenty of drug addicts attribute their sobriety to getting closer to God. According to a certain counsellor, a relationship with spirituality is what separates those who stay sober from those who continue to relapse. ${ }^{71}$ Restorative programmes will therefore be designed around what values the drug users hold dear. This taking into account of what the users respond to and acting accordingly is precisely what responsive regulations advocate. Everyone gets a fair shot at the best treatment as opposed to being chosen by a process concerning which they have no voice. The method ensures that the addicts are all targeted to ultimately have a change in behaviour, as the core issues can be resolved.

In this way, the drug user will understand that he is important and valued and that there is a genuine desire on the part of the system to actively help him. Hopefully, this will in turn restore his confidence in the efforts, thereby encouraging him to wholeheartedly follow through the pyramid of criteria until favourable results are attained. Now, because the responsive approach advocates for context, the addicts will be relocated to an island in an endeavour to create the circumstances vital for the restorative criterion to thrive. Whereas separation is undoubtedly beneficial for the restoration of a drug user, it also serves to ease pressure on family members and the community, who constantly bear the brunt of the drug user's maladaptive ways. In fact, an interview with family members of users in Seychelles revealed a common 90\% sentiment that their user family member ought to be separated from their homes when undergoing treatment.

With the drug addicts gone, the more flagrant and pressing problems on the ground that are ordinarily associated with drug use will be dramatically reduced. For the community, this affirms the government's obligations to them too. Undoubtedly, a reduction on the main islands of drug-related offences can only be immediately observed should police officers correctly identify the users on the basis of the new presumptions delineated earlier in this section. The Seychelles has some 115 islands, the majority of which are completely uninhabited. The subject of deliberation in Parliament will be the possibility of sending drug users to one of these islands, where the rehabilitation centre would feature. This would mean abandoning the proposal to have the now-redundant Centre Mont Royal

71 Jeffery Juergens, 'How being spiritual helps in addiction recovery' (October www.addictioncenter.com/community/how-being-spiritual-helps-in-addiction-recovery/ <accessed 4 September 2020>. 
refurbished in situ and discarding the new proposal for a rehabilitation Centre at Montagne Posée. The rationale behind this is to get the drug user as far away as possible from the very place which fuelled his addiction in a bid to create the context that makes responsive regulation effective.

According to Cambodia's Addiction Centre website, a drug addict who travels for the purpose of rehabilitation gets into the mindset that he is in fact on a mission towards recovery. He becomes actively conscious that he is on a path to a fresh beginning somewhere new. For many, the act of distancing themselves from their triggers douses the desire to fall back into the habit. A physical separation reinforces their dedication to sobriety and to their treatment strategy, thereby forcing them into some level of commitment, ${ }^{72}$ which is otherwise easily broken when methadone is administered on their home island from a van immediately prior to their release back into the community, where they are left to their own devices. For the drug user, being away from home will also allow him time to reflect upon his objectives. The idea of creating a different but apposite context for the drug user is a rather complex endeavour but not an impossible one. Context for the purpose of restoring Seychellois will mean the creation of a district not only having the bare necessities required to get the drug users by while in isolation, but also creating an environment where the drug users thrive and live their lives to the fullest in a place filled with love and care. A conducive environment as such requires human understanding and participation for its fulfilment, an effort which cannot be achieved solely via legislation.

Jonathan Hari, a British writer and journalist, explains how the early 20th century rat experiment for heroin, which described that a rat is likely to choose heroin water rather than pure water, was discounted by Bruce Alexander, professor of psychology in Vancouver, when after a rat park comparable to heaven on earth (for rats) with every fun thing the rats needed was built, the rat there almost never consumed the drug water and never did they overdose. The percentage of rat overdose plummeted from $100 \%$ when isolated to $0 \%$ when they had happy and connected lives.

Hari considers two crucial aspects: (1) giving the rats a happy life and (2) keeping them connected with society. He cites the Portuguese model as that model which effectively encompasses these two aspects. ${ }^{73}$ I subscribe to the view that users ought to be given happy lives. However, keeping the addicts connected to society has not proven feasible in the Seychelles' context, where legislation in fact currently mirrors the Portuguese model. Whereas the positive effects of decriminalization were almost instant in Portugal, ${ }^{74}$ the opposite can be said for the Seychelles. Could this be because a mere alteration to the law is inadequate?

72 Addiction Centre, 'Should I travel to rehab' www.addictioncenter.com/rehab-questions/should-itravel-for-rehab/ <accessed 22 September 2020>.

73 Jonathan Hari, 'Everything you think you know about addiction is wrong' (June 2015), www.ted.com/talks/johann_hari_everything_you_think_you_know_about_addiction_is_wrong? language =en $\langle$ accessed 21 September 2020 $>$.

74 Susana Ferreira, 'Portugal's radical drugs policy is working, Why hasn't the world copied it?' (December 2017) www.theguardian.com/news/2017/dec/05/portugals-radical-drugs-policy-isworking-why-hasnt-the-world-copied-it <accessed 21 September 2020>. 
For Portugal, decriminalizing drug use meant a rapid stabilizing in the opioid crisis, the decline in the ensuing years of HIV and hepatitis infection rates, overdose deaths, drug-related crimes and incarceration rates. However, Ferreira suggests that it is misleading to credit these results wholly to a change in the law. There was an enormous cultural shift, he says, in how the country perceived drugs, addiction and itself. In many ways, the law was merely a reflection of transformations that were already happening throughout the land. The language began to shift, too. No longer were users labelled drogados (junkies); rather, they were more sympathetically referred to as 'people who use drugs' or 'people with addiction disorders'. This, too, was crucial. Could this lack of shift in culture perhaps be the reason why the approach has been ineffective in the Seychelles?

I created a poll wherein the public was required to say whether they perceived a drug user as a victim of a disease or as an offender. According to the poll, $33.3 \%$ felt that drug users are offenders. ${ }^{75}$ Surely, this high percentage is indicative of the true sentiments of the people of Seychelles. Consequently, acceptance of the users and connectivity is rendered nearly impossible. For the user, resentment by society might hinder his progress as he is plagued with shame. Thus, Hari's theory ought to be implemented to the extent that we provide addicts with a sympathetic and caring environment. However, his view on immediate integration has not availed to much in the Seychelles; thus, their the addicts' relocation to a different island would work better in our context as the people have not yet developed the sympathy towards the addicts required for the Portuguese model to work as is. It is worth noting that sending addicts to an outer island has once before been attempted, whereby addicts embarked on a rehabilitation programme on Coëtivy which did not involve the methadone treatment. ${ }^{76}$

In August 2016, the Minister for Home Affairs, Charles Bastienne, under whose purview the programme fell, expressed his satisfaction with the programme and the positive attitude that the addicts exhibited thereafter. The facility was designed to provide for medical treatment and a rehabilitation programme which included early morning reflections, work, counselling, physical exercises and sports. Users were able do work suitable for the Seychelles' context. The persons following the programme exclaimed their satisfaction, thereby encouraging others with an addiction to pursue the same. Evidently, with this endeavour, the government headed in the right direction as the project yielded results.

However, while Roland St. Ange described the programme as 'fantastic' and having suitable counsellors, he also complained about the unavailability of the promised healthcare personnel, who were to be present on the island regularly, and the lack of dental care facilities, which meant that a simple stomach or

Amelie Nourrice, 'Heroin use in Seychelles' https://poll.app.do/polls/heroin-use-in-seychelles/ results.

76 Seychelles Nation, 'Drug addiction: Minister satisfied with detox programme on coetivy' (August 2016) www.nation.sc/archive/250525/drug-addiction-minister-satisfied-with-detoxprogramme-on-coetivy <accessed 22 March 2021>. 
toothache was not dealt with in a timely manner. These concerns were echoed by the drug user patients themselves. ${ }^{77}$ The idea is to reinstate the outer island rehabilitation to create the apt context, as its trajectory was rather promising, all the while ensuring, this time, its self-containment (through its running in a manner similar to that in which a district in the Seychelles is run) to avoid failure.

This means that the key components associated with a district, such as a religious establishment, a dental care facility, a police station, a bank and a clinic, ought to be available on the island. This is to ensure the comfortable atmosphere previously spoken of, wherein the user's well-being is upheld and the purpose for which he is sent to the islands is fulfilled in a humane and sympathetic way. In Seychelles, a district running through as little as 3 square kilometres is very well capable of effective functioning. The Anse Aux Pins district, for instance, occupies a minimal surface area yet easily caters to each individual's needs.

Thus, contrary to how rehabilitation was run on Coëtivy Island, the new method will build on that idea but with an active understanding that the deficiencies experienced in the previous attempt will not be repeated in the new proposal. An away-from-home outer island rehabilitation programme could on this basis prove successful.

It is of utmost importance that a person involved in any manner of trade and who enters the island to render a service is enlightened as to the importance of preserving the conducive context needed for the users to thrive. This requires regulations setting out protocols for entry into the island. Persons coming in must be subjected to scrutiny and screening in an endeavour to establish their trustworthiness, their incorruptibility and to ensure that they thoroughly understand the importance of the context that is sought. The right structure prior to entry must therefore be established. Clearly, legislation, although required for what has beenformerly described cannot by itself produce the practical setting that is sought. Neither can it shift perceptions and cultures; this can only be achieved by those with an understanding of what it is that needs to be achieved and a desire to achieve it in a principled and practical manner, which is why creating the right context on the island is essential.

As mentioned previously, a responsive approach denotes the engaging of various actors, which makes the whole method more effective; hence, the psychologists, spiritual advisers and so on. The government cannot presume to finance, on its own, all the intricacies associated with the implementation of Braithwaite's method. When Moumou launched the revamping of the Centre Mont Royal building project, 2 million Seychelles rupees $(£ 85,748.04)$ had been raised. This is indicative of a keen inclination on the part of the public to help in this endeavour. Whereas the government's justification for putting a stop to the raising of funds for the Centre Mont Royal Project was based on the fact that the building was government property and as such the burden of renovation rested upon it, by building a different centre on another island, the pressure of carrying on the project alone is relieved. 
Although the Centre Mont Royal restoration project never took off, it would appear that it may not be for a lack of finances, because the National Assembly, late last year, approved a budget of R73,233,000 ( $£ 3,139,590.31)$ for APDAR, of which 10 million $(£ 429,604.40)$ has been assigned to the construction of its rehabilitative village. Other than the government's financial commitment to APDAR, the UAE has agreed to fund and help design a drug rehabilitation Centre at Montagne Posée on the main island of Seychelles, an endeavour which entails the training of Seychellois personnel for the Seychelles' Rehabilitation Centre. The new Centre to be financed by the UAE will, according to President Faure, cost USD3.6 million $(£ 2,794,302.00){ }^{78}$

It is clear that there is a concerted effort by very willing and capable actors, who do not necessarily directly influence each criterion, to raise capital for rehabilitative purposes. In fact, in a personal communication with a former economist of the Central Bank, the latter suggests that the government of Seychelles is very well capable of setting up a financial mechanism for a more adventurous outer island rehabilitation project as described. However, such a project must be within reasonable parameters. ${ }^{79}$ Furthermore, there ought to be an assurance that the project will be feasible and that it is one having the relevant backing from anyone possibly having a vested interest in the project. This is to avoid a situation comparable to that of the Marie Louise Island debacle. The government of Seychelles had established, in 2012, prisons on Marie Louise Island to house convicted drug traffickers, but these were closed abruptly following complaints of poor treatment and substandard care of prisoners within the facility. ${ }^{80}$

A cohesive effort in raising finances of course ensures materialization of the entire project and accountability to all the stakeholders that the finances are properly utilized to develop the island in the aforementioned manner in the right context or circumstances for the restorative criterion to be effectively exhausted. Sufficient capital, accountability to financial providers and the right context will lead to success.

Having drug addicts concentrated on a small island in order to create the apposite context/circumstances previously outlined in this article will make for easier monitoring of persons coming into the islands and additionally help to contain possible altercations between those already on the island. The need for security provides an opportunity for the hiring of private security companies equipped with drones and telescopic cameras. Again, the idea is to involve as many actors as possible, although not directly influencing each criterion, in order to keep corruption at bay.

The Seychelles is renowned for being big on importation, from fruits and vegetables to furniture. What is commendable is that with regard to the

79 Former Economist of Central Bank, personal communication (20 August 2020).

80 Ismail Akwei, 'Seychelles transforms island prison for drug traffickers into military training camp', $\quad$ www.africanews.com/2017/10/03/seychelles-transforms-island-prison-for-drug-traf fickers-into-military-training// <accessed 21 September 2020>. 
redundant Coëtivy rehabilitation project, the government was able to identify the type of work that the users could do, on the basis of Seychelles' needs, to somehow contribute to the economy. This concept, if introduced into the proposed outer island rehabilitation project, is a practical way for users to give back to the country and concurrently prepare for their reintegration into society in terms of developing manual talents.

According to the Principal Biosecurity Officer at the National Biosecurity Agency in Seychelles, Ravi John Moustache, as there are extremely rich virgin soils on the outer islands, the first crops would benefit. This would cut back on importation costs of fruits and vegetables. ${ }^{81}$ Farming has proven particularly essential to the Seychelles during the Covid-19 pandemic, with the population being forced to rely on whatever is produced locally. This could potentially be the beginning of a new dawn for Seychelles. However, according to Moustache, because Seychelles does not generally have soil conducive to massive production, to be effective, this endeavour would require the government to maximize the use of natural resources and add value thereto and cultivate low-maintenance crops such as pumpkin and cassava.

Thus, the relocation of the users for context inadvertently facilitates their monitoring, creates an environment within which they can develop their talents and contribute to the economy in preparation for their reintegration into society. Restoration can only be effective when the police, the legislature, the executives, the mental healthcare specialists and the public work together to actively ensure that the restoration of the user is achieved.

\section{The Rational Actor}

By offering to deter the user via the threat of incapacitation, this method serves to give him a second chance at rehabilitation, if the first attempt at restoration fails. Deterrence of drug use will be effective because it will be done in a very strategic manner, in a specific context that allows the user to comprehend where he is with regard to his position in the pyramid. The tone of Braithwaite's method changes once deterrence efforts are made, as the true consequences of the user's offence at the deterrence criterion become imminent. Here, the involvement of someone representing authority will be used to create that change in tone. According to Britannica, a police is the representation of the civil authority of the government. Police work has developed considerably from what it was centuries ago. ${ }^{82}$ Therefore, employing the police as one of the actors to drive home the imminent consequences into the user is apt, as the job of the police is not set in stone. This authority that the police exhibits expectantly presents the user with a reality check. This setting is exactly the context needed for the deterrence criterion to thrive.

According to Valerie Wright, research to date commonly suggests that deterrent benefits are more likely produced when punishment is certain, rather

81 Ravi Moustache, Principal Biosecurity Officer, personal communication (4 August 2020).

82 www.britannica.com/topic/police <accessed 20 August 2020>. 
than it being severe. ${ }^{83}$ Daniel Nagin and Greg Pogarsky, leading scholars on deterrence, state that

punishment certainty is far more consistently found to deter crime than punishment severity, and the extra-legal consequences of crime seem at least as great a deterrent as the legal consequences. ${ }^{84}$

\section{Wright suggests that}

if there was $100 \%$ certainty of being apprehended for committing a crime, few people would do so. But since most crimes, including serious ones, do not result in an arrest and conviction, the overall deterrent effect of the certainty of punishment is substantially reduced. ${ }^{85}$

Braithwaite's approach ensures the type of certainty that Wright discusses, in that once the drug-driven offender is made aware by the police that he has reached the deterrence tier of the pyramid, he would realize that all the previous tiers of the pyramid have faithfully been exhausted and thus nothing hinders the enforcement of the ensuing tier, specifically incarceration, creating a sense of certainty that punishment is imminent. ${ }^{86}$

\section{However,}

according to deterrence theory, individuals who consider using drugs will weigh the expected rewards of using against the subjectively perceived risk of punishment [and] should choose not to use when the expected legal risks outweigh the expected rewards. ${ }^{87}$

There is thus a presumption of rationality on the part of the actor. The theory has been subject to many criticisms and condemned for making the following assumptions:

1 That the people know what the penalties for a crime are

2 That people have good control over their actions

3 That people think things through and make choices about their behaviour on the basis of logic, not passion ${ }^{88}$

83 Valerie Wright, 'Deterrence in criminal justice' (November 2010) www.sentencingproject.org/ wp-content/uploads/2016/01/Deterrence-in-Criminal-Justice.pdf <accessed 3 August 2020〉.

84 Daniel Nagin and Greg Pogarsky, 'Integrating celerity, impulsivity, and extralegal sanction threats into a model of general deterrence: theory and evidence,' Criminology, 39(4), 2001.

85 Ibid.

86 Amelie Nourrice, 'Smart regulations for alcoholism' (31 May 2020).

87 Jeffery Cece, 'The impact of the severity of punishment on drug users and sellers abbreviated.pdf (January 2012) https://upload-assets.vice.com/files/2016/11/01/ 1478026703The_Impact_of_the_Severity_of_Punishment_on_Drug_Users_and_Sellers_Abbre viated_.pdf <accessed 21 September 2020>.

88 Study.com, 'Deterrence theory of punishment: definition and effect of on law obedience' https:// study.com/academy/lesson/deterrence-theory-of-punishment-definition-effect-on-lawobedience.html <accessed 3 August 2020 >. 
Whereas these assumptions may be rightly rebutted under a different set of circumstances, they are perfectly apt in this instance.

The question of the user being unaware of the penalties will not arise under this approach for the reason that the penalties otherwise associated with his offence will be conveyed to the drug user/offender from the very moment he embarks on his journey depicted in Braithwaite's model. ${ }^{89}$ Moreover, although it might appear logical to not assume that everyone has good control over his actions, to refute the deterrence theory on this basis goes against the general principle of the presumption of capacity, which is that individuals are presumed to have mental capacity when committing an act. Otherwise, the implication would be that the majority of people make decisions when their judgment is impaired, which is not the case.

If there is already a presumption in law that a person is deemed to make a decision while he is fully capable, why then should drug consumption not be presumed to be committed while the person has full control? With regard to the third presumption, contrary to perhaps a crime of passion, which can occur on the spur of the moment when one is driven by anger and blinded by rage, a decision to take drugs is oftentimes a choice thought through despite being fully aware of the repercussions. For instance, those individuals who consume drugs for dousing their pain and hurt find themselves going through some type of logical thinking in seeking out a solution for their distress. In fact, according to the National Institute on Drug Abuse, people use drugs because they want to feel good, stop feeling bad, perform better in school or at work or are curious because others are doing it and they want to fit in, ${ }^{90}$ thereby making a decision on the basis of some form of logic, although arguably warped. ${ }^{91}$ Thus, whereas stabbing someone with a fork at a dinner table could be construed as an act of passion, drug use cannot necessarily be perceived as such.

However, in the unlikely event that the addicts initially take drugs on a whim, there is bound to be some point in the pyramid where they are compelled to do some critical thinking pertaining to their choices and the importance of sobriety as they go through treatment. Thus, deterrence is apt in the circumstances and its placement just short of the apex is critical in that it occurs subsequent to the tiers which have furnished the drug user with enough resources to help him make a logical decision as to what to do next, that is, repeat the previous tier or risk incapacitation. The pyramid accurately gives effect to what the International Narcotics Control Board states about deterrence with regard to the current addicts in that it encourages them to go to rehab, which is essentially what will primarily serve efficacy.

89 Nagin and Pogarsky, 2001, note 84.

90 National Institute on Drug Use, 'The science of drug use: discussion points' www.drugabuse.gov/ drug-topics/criminal-justice/science-drug-use-discussion-points <accessed 3 August 2020〉.

91 Ibid. 


\section{$V \quad$ The Irrational Actor}

Under this approach the drug addict is not permitted to adopt a victim mentality likely to preclude him from taking any responsibility at all. Therefore, although the pyramid is patient in offering sympathy in the initial stages of the process, this sympathy eventually wears out as the apex of the pyramid becomes imminent. Thus, this method offers a combination of both sympathy towards the user and eventual penalty if he refuses treatment and slips back into addiction and his maladaptive ways. The user cannot persistently ride on his 'victim label', thereby escaping the undesirable consequences associated with him constantly victimizing and offending the people around him. He is at this tier compelled to want to get his act together and understand that in the same way that the government has a duty towards him, he has a duty towards society. He understands that the government is still willing and able to do everything necessary to protect the community, even from him. In fact, the Constitution of Seychelles defines explicitly every citizen's right, which in turn places an obligation on the user towards others. For instance, Article 26 gives every individual the right to the peaceful enjoyment of his property; Article 38 upholds every person's right to a safe environment. For every right there is a corresponding obligation, from which a user should not be exempt.

The drug user, who has undertaken to follow the various steps of the pyramid, forfeits his right to back out once he embarks on this journey. As previously mentioned, this cannot be construed as an unjustifiable infringement of his freedom because he has essentially contracted into following Braithwaite's method in lieu of facing the harsh consequences of his offence. He embarks on what can be likened to Hobbes' social contract, which in principle means giving up some individual liberty in exchange for some common security. ${ }^{92}$ Regardless, because both consumption of drugs over the prescribed limit and drug-driven offences are punishable under the law, backing out of the journey would mean that the user would face the rightful punishment associated with the offence, a consequence he is likely to avoid.

The wonderful aspect of this pyramid is that it offers de-escalation. Therefore, a user who exhibits relapsing tendencies may repeat the previous tiers of the pyramid until sobriety is attained. It is unlikely that a user will reach the apex. However, in the unlikely event that he does, efficacy still needs to be served. The pyramid was created with an understanding that each tier will serve a purpose. Thus, although we would typically expect positive results in a user before the final tier of the pyramid, a user may reach the summit.

Incarceration being the last step in the pyramid means that drug users are not afforded the same treatment as in the previous tiers. The apex of the pyramid signifies punishment for the drug-driven offence. The deterrence tier ought to have made it very clear that addicts have no choice but to shake their addiction cold turkey while incapacitated. Although sobering up cold turkey as opposed to

92 'Thomas Hobes: social, contract' https://oregonstate.edu/instruct/phl201/modules/ Philosophers/Hobbes/hobbes_social_contract.html\#: :text=The\%20condition\%20in\%20which \%20people,the\%20right\%20of\%20natural\%20liberty <accessed 19 August 2020〉. 
tapering off could, according to Healthline, make quitting easier on the basis that users believe that complete riddance causes less temptation, quitting addictive drugs cold turkey may not be the most effective way forward. ${ }^{93}$ This is because drugs cause changes to the brain, resulting in the drug user developing painful withdrawal symptoms and a powerful urge to start using the substance again. It can also even lead to death when he decides to quit. ${ }^{94}$

A drug user ought to, for these reasons, avoid this tier at all cost. Although this final effort could be construed predominantly as serving to protect the community from the dire consequences of drug use, despite not being rehabilitative, it is not completely unfavourable to the user. In a video from the U.S. Senate Forum on Addiction wherein Dr. McLellan explains how it is imperative to not throw away sanctions when it comes to drug addicts, he acknowledges how his drug-addicted son would have died if not for him being sent to jail. He explains how we cannot throw away sensible sanctions but instead work in partnership with the criminal justice system to achieve optimal results. ${ }^{95}$ Indeed, what Dr. McLellan remarks here is exactly what is reflected in Braithwaite's pyramid: a method cognizant of both treatment and punishment, which is apt for the Seychelles' context as it aims to protect both the user and the community.

The pyramid therefore offers at this tier to appease a small community plagued with the dire and flagrant effects of drug use, which have left it unable to destigmatize the offenders and thus unable to exercise the patience required to establish a connection with the users. Despite the users having forfeited help or failed in the previous tiers of the pyramid, they ought still be afforded a safe place while incapacitated. Unfortunately, there have been instances where drugs have been smuggled into the Seychelles' prisons. ${ }^{96}$

However, the government, in 2016, introduced an amending provision in the Prisons Act which keeps drug-dependent persons convicted under the MODA separated from other prisoners, potentially keeping them away from where drugs are smuggled. ${ }^{97}$

As cold turkey deaths are possible at this tier, steps ought to taken to prevent deaths and to avoid a situation similar to that of the infamous Tyler Tabor case, where an American man died of dehydration at the Adams County jail as a result of drug withdrawal. David Lane, the attorney representing the Tabors, stated that "[i]f the jails are not trained and they're not ready for it, you get a Tyler Tabor". ${ }^{98}$

93 Stephanie Watson, 'Is it safe to quit substances Cold Turkey? Here's what to consider (January 2020) www.healthline.com/health/opioid-withdrawal/quitting-cold-turkey\#safety <accessed 4 August 2020>.

94 Ibid.

95 Addiction Policy Forum, 'Why do we have to put drug users in jail?' www.youtube.com/watch? $\mathrm{v}=\mathrm{kFgdV} 8 \mathrm{Z} 8 \mathrm{STE}$ <accessed 4 August 2020 >.

96 Seychelles Nation, 'Montagne Posée Prison' (February 2016) www.nation.sc/archive/248462/ montagne-posee-prison <accessed 24 August 2020 >.

97 ANU TV, note 10.

98 Julia Lurie, 'Go to jail. Die from drug withdrawal. Welcome to the Criminal Justice System' (February 2017) www.motherjones.com/politics/2017/02/opioid-withdrawal-jail-deaths/ <accessed 4 August 2020>. 
According to Part 2 of the Prisons Act, the Seychelles has in place medical government officers who are assigned to the prisons and tasked with the general care of the prisoners. They perform such duties prescribed by law. However, they are not given the task to deal with a withdrawal situation instantaneously. Those suffering from withdrawal are rather sent to the Seychelles Hospital for treatment. $^{99}$

Although the Minister of Health is bestowed with regulation-making power to define the parameters of the medical officer assigned to the prison, none have been made so far. The 2016 Amendment shows a willingness on the part of the government to cater to the user's needs and safety. Legislation ought to therefore allow for the setting up of a system whereby medical officers are able to effectively deal with withdrawal cases as and when they occur. Thus, for optimal efficacy at this tier, the jails ought to cater to users' health and safety to guarantee results for both the users and the community while the latter enjoys its freedom. Legislation is required here but a willingness on the part of those in charge of the prisons is imperative to create the right context for the drug users to benefit even at this final tier.

\section{F Conclusion}

This article sought to find a new way to curtail drug use in the Seychelles as opioid consumption on the islands continues to escalate, resulting in a surge in drug-related crimes. Whereas there are two globally recognized ways that governments keep drug use at bay - by either waging a 'war on drugs' or treating the drug addicts as victims of a mental disease - this article employed the responsive approach which finds expression in Braithwaite's pyramid and which somehow aptly combines both approaches, as a combination is what Seychelles' context warrants. Under this approach the interests of both the user and the community are upheld, a move which runs contrary to the current reality where the community's sentiments are often dismissed.

Intercepting drugs and apprehending drug traffickers have not been straightforward. The adducing of evidence pertaining to the very elusive drug lords poses problems, and when drug traffickers are apprehended, their cases are not easily concluded. Targeting the drug user is the most practical manner in which efficacy may be served as users make for easier targets in that they are less elusive than traffickers. Moreover, they are also those most affected in terms of health and stature when it comes to the epidemic. They are those seen to be disturbing the peace. So, efficacy is served when a swift clean-up of the streets occurs by pursuing the easiest targets.

It is for the aforementioned reasons that this article suggests that the right presumptions of who the targets are be made from the very outset to allow for their quick embarkation on their journey towards sobriety. New presumptions ought to feature in the law. The article 
a described what the current efforts in curtailing drug use in the Seychelles are;

b discussed the problems with these efforts and why they avail to nought;

c foresaw what the situation will look like under the responsive approach (using Braithwaite's criteria); and

$\mathrm{d}$ discussed why the responsive approach will work better, thereby serving efficacy.

MODA, which is substantially reflective of the Portuguese model, has not had the desired effects the Seychelles had hoped for. Thus, because the people's mindset has not been renewed in a way so as to sympathetically perceive drug users in a different light, a connection with the users by the community has not been established. By taking a more lenient approach with user offenders, the government has caused the users to perceive themselves as victims, thereby encouraging them to adopt this victim mentality as part of their own. This creates frustration within the community as it makes it more difficult for drug users to take responsibility for their actions. Despite efforts under MODA, there remains a surge of repeat offenders on relapse and Seychelles remains the country with the highest percentage of heroin consumption per capita globally.

The efforts under APDAR likewise leave a lot to be desired. The most disconcerting aspect of the effort towards restoration under APDAR is that despite a higher number of patients on the low-threshold programmes, the drug addicts are given less interventionist attention by the Agency and are excluded from psychological interventions, resulting in a plethora of repeat offenders. Besides the aforementioned, the rehab Centre, which ought to have been available under APDAR, is not yet built. Moreover, although help from other countries is in a lot of instances warranted, these relations tend to occur in a bid to catch drug traffickers rather than assist drug addicts.

By employing the criteria of Capacity building, Restorative, Deterrence and Incapacitation, we are able to combine the two ways of battling drug addiction first, acknowledging that the drug user is a victim of a disease and thereby providing suitable treatment in the most practical environment, and second, treating the drug users as the offenders they are once they persist in their deviant behaviours. The drug user is offered sympathy at the initial stages of the process, whereby his capacity is built, but if failing at that, he undertakes rehabilitation. The user, under the proposed method, is precluded from adopting a victim mentality because despite the first tiers of the pyramid, he will at some later time be responsible for his actions as illustrated in the pyramid if he persists in his maladaptive ways. This is indicative of the government's commitment to the public at large, reaffirming its obligations towards the latter.

The responsive approach being true to culture, religion, context allows us to decide who the actors are and where best and in what circumstances Braithwaite's criteria will thrive in order to serve efficacy. The criteria thus must be employed under the circumstances delineated in Section 5; hence, for instance, the need to have created a particular atmosphere at the deterrence tier, the possibility of spiritual guidance and for restoration to take place on a separate island since 
connection with the addicts has been nearly impossible. A different location means a lesser possibility of relapse and a reduction in drug-related offences on the main islands, which in turn offers peace and tranquillity to the family members and the community at large. Most importantly, it allows for the creation of an environment which is needed for the restorative criteria to thrive.

Under Braithwaite's model, all persons presumed to be drug afflicted will go through a restoration process, which includes psychological interventions, as opposed to what is currently offered under APDAR. This will improve the chances of a successful weaning off the substance as the core issues for all concerned are being dealt with and resolved. The pyramid necessitates a number of actors who either work in conjunction with each other at each criterion or who respectively take over when one actor fails as each tier is exhausted. As such, there is a concerted effort to combat the plight and without dismissing the law. The burden to see the process until the final stages is thus shared among mental health professionals who provide mental healthcare, spiritual leaders, police officers who aptly recognize the targets and who set the tone for deterrence, the judiciary and the community. This makes the process more efficacious as the burden is shared. This combination and the use of various actors at each tier is a significant way to effectively execute government policies without the strict and direct regulator/ regulatee relationship whereby the former would otherwise lord it over the latter.

A rehabilitation project on the scale that this article proposes is almost certainly promised as both the government and the public have shown a keen interest in the contribution towards the abating of drug consumption. Having various actors commit to assisting financially has the practical result of increasing the likelihood of the project taking off as there is a need to ensure that finances are being used for the purpose for which they have been provided.

The government must be advised of the utmost importance of ensuring practicality - that the right environment is created, the apt actors are on board and there is no repetition in the new proposal of the miscalculations and deficiencies demonstrated in the previous and current efforts, which in some vague and less favourable fashion resemble certain aspects of Braithwaite's approach, but which have proven rather unmethodological, without the government having an understanding of the importance of escalating efforts, emphasis on different actors, context, culture, and which as a result, have led to failure. It is for the drafter, with an understanding that efficacious regulation for the curtailment of drug use far transcends legislation, to encourage the government to adopt this approach whenever a proposal concerning the issue at hand is warranted. 